http://dx.doi.org/10.5007/2175-795X.2012v30n1p19

\title{
Gestão pedagógica na educação a distância: análise de uma experiência na perspectiva da gestora
}

\author{
Roseli Zen Cerny*
}

Maria Elisabeth Bianconcini de Almeida ${ }^{* *}$

\section{Resumo}

$\mathrm{O}$ artigo analisa um sistema de gestáo pedagógica desenvolvido em uma instituição pública de ensino superior durante a implantaçáo dos primeiros cursos de licenciatura a distância. Os pressupostos teóricos embasam-se no referencial da gestáo dos sistemas educacionais. O sistema foi construído a partir da perspectiva de trabalho colaborativo e se ancora na tríade formação, produção de materiais e pesquisa e avaliaçáo. A metodologia de pesquisa é a qualitativa e o método é o da auto-observaçáo. $\mathrm{Na}$ análise, ficou evidenciado que as principais dificuldades para a implantaçáo de cursos a distância sáo: a história da $\mathrm{EaD}$, a cultura do presencial, o modelo pouco flexível de organizaçáo institucional, as políticas públicas e a burocracia. Na organizaçáo das equipes, há a percepção de que a gestáo pedagógica reproduz em parte o modelo vivenciado no presencial no que se refere à parceria entre os centros formadores de professores. Evidenciou-se que a construçáo coletiva do trabalho demanda tempo e abertura por parte das equipes. É possível concluir que o trabalho integrado de formaçáo, de produçáo de materiais e de pesquisa e avaliação contribue para uma atuaçáo mais orgânica na educaçáo a distância, quebrando os paradigmas fordistas encontrados nas experiências com esta modalidade de ensino.

Palavras-chave: Educação a Distância. Gestão - Educaçáo a Distância. Formaçáo de professores.

\footnotetext{
* Doutora em Educaçáo pela PUC-SP. Professora do Centro de Ciências da Educaçáo da Universidade Federal de Santa Catarina.

** Doutora em Educaçáo pela PUC-SP. Professora do Programa de Pós-Graduaçáo da PUC-SP.
} 


\section{Educação a Distância nas Universidades Federais: um novo desafio para a educação superior brasileira}

A necessidade de formar novos professores para dar conta das crescentes e urgentes demandas por educaçáo - a exemplo da explosáo do ensino médio no nosso país, cuja populaçáo de matriculados cresceu mais do que o dobro na última década ${ }^{1}$ enquanto o contingente de egressos das licenciaturas cresceu timidamente - aponta para a responsabilidade social de a rede federal de ensino superior assumir essa tarefa. Considerando que, historicamente, as políticas priorizaram a expansão do ensino superior por meio da iniciativa privada, sob a qual está a responsabilidade de mais de $80 \%{ }^{2}$ deste nível de ensino no Brasil, e que, tradicionalmente, estas universidades têm ofertas restritas de cursos de licenciatura, por serem cursos pouco rentáveis, a demanda recai sobre as universidades públicas, que precisam incorporar novas estratégias para preencher a lacuna na formaçáo de professores.

A educação a distância passa a ser uma opçáo viável para atingir a meta de formar um número expressivo de professores em um curto período de tempo. Esta é a estratégia adotada pelo Ministério da Educação nos programas de formaçáo de professores. Neste sentido, vários programas estáo sendo coordenados pelo MEC; dentre eles destacam-se: 1) o Pró-Licenciatura, lançado no final do ano de 2004; e 2) a partir de 2006, a Universidade Aberta do Brasil.

Diante deste contexto, as universidades públicas sáo chamadas a participar desta iniciativa com mais intensidade do que se fez até hoje. Algumas universidades já possuem experiências consolidadas nesta modalidade, com oferecimento de cursos de graduaçáo a distância, mas, para a maioria, esta é uma iniciativa pioneira.

\section{O contexto}

A instituiçáo onde a pesquisa foi realizada é a Universidade Federal de Santa Catarina (UFSC). Nesta universidade, os primeiros cursos de licenciatura a distância provêm da candidatura em edital aberto pelo Governo Federal, por meio da Secretaria de Educação a Distância (SEED) do Ministério da Educaçáo, na Chamada Pública 01/2004 (BRASIL, 2005). O programa, denominado Programa de Formaçáo Inicial para Professores dos Ensinos Fundamental e Médio - Pró-Licenciatura, propunha a organização de licenciaturas para formar 
"professores que atuam nos sistemas públicos de ensino, nos anos / séries finais do Ensino Fundamental e/ou no Ensino Médio e não têm habilitaçáo legal para o exercício da funçáo (licenciatura)" (BRASIL, 2005, p. 3). Neste Edital, a SEED selecionou treze Instituiçóes Públicas de Ensino Superior (IPES), com o objetivo de ofertar 17.585 vagas em cursos de licenciatura a distância em Física, Química, Biologia, Matemática e Pedagogia para Educaçáo Infantil, Jovens e Adultos e Educaçáo Especial

A UFSC foi uma das instituiçôes contempladas para o oferecimento dos cursos de Física e Matemática. Para tal, foi estabelecida, no ano de 2004, a Secretaria de Educaçáo a Distância, ligada diretamente ao Gabinete do Reitor, como órgáo responsável pelos cursos na modalidade a distância. Para a realizaçáo dos cursos de licenciatura nesta modalidade educacional, foi criada, ainda, uma estrutura sob a responsabilidade do Centro de Ciências da Educaçáo (CED) em parceria com o Centro de Ciências Físicas e Matemáticas. No CED, essa unidade está localizada no Laboratório de Novas Tecnologias (Lantec) e se denomina Coordenaçáo Pedagógica dos Cursos de Licenciatura a Distância.

Cabe salientar que é neste período e no âmbito do Pró-Licenciatura que o Centro de Ciências da Educaçáo passa a discutir, pesquisar e fazer educaçáo a distância. Não é, ainda, uma posiçáo hegemônica no centro, mas abre-se um espaço importante de atuaçáo e discussáo sobre a educaçáo a distância nesse local - o que é muito positivo, uma vez que essa iniciativa comporta vários desafios e diversas possibilidades no terreno da formaçáo de professores e da gestâo de cursos na modalidade a distância, uma realidade nova para muitas equipes e universidades.

\section{Gestão de Sistema de Educação a Distância}

A organizaçáo de um sistema de $\mathrm{EaD}$ pode ser pensada de diferentes maneiras, dependendo da concepçáo que se tenha de educaçáo. Mais estritamente, a organizaçáo de um sistema de educaçáo a distância é mais complexa, às vezes, que um sistema tradicional presencial, visto que exige náo só o desenvolvimento de materiais didáticos específicos, mas também a integraçáo das tecnologias e a presença de especialistas nesta área (PRETTI, 1996). Outros fatores também contribuem para a sofisticaçáo da gestáo na educaçáo a distância; entre eles, destaco a falta de cultura para atuar na $\mathrm{EaD}$ e a comunicaçáo entre os docentes e alunos, que deixa de ser face a face. 
A gestáo, na educaçáo a distância, é um processo que envolve a organizaçáo e a operacionalizaçáo de um sistema que viabilize as açóes técnicas e políticas de todos os envolvidos. Pretto reforça esta postura quando diz que "fazer opçáo pelo ensino superior a distância é uma decisão política” da instituição. Ele considera que náo podemos propor um projeto de $\mathrm{EaD}$ naturalizando a crise em que estáo imersas as universidades, visto que os problemas "irāo emergir no próprio contexto de produção e realizaçáo da EaD" (PRETTO, 2005, p. 46). A educação a distância não pode ser utilizada como um subterfúgio e iniciar com a responsabilidade de resolver problemas antigos das instituiçóes, em especial a falta de verbas. Pelo contrário, com a implantaçáo da $\mathrm{EaD}$, "novos problemas podem começar a fazer parte dos desafios das universidades, devido à impossibilidade de sobreposiçáo da cultura de formaçáo presencial sobre a cultura de EaD" (PRETTO, 2005, p. 46). O caminho apontado por Pretto (2005) é a construçáo de um projeto institucional de $\mathrm{EaD}$ na universidade que envolva a singularidade local, além do caráter sistêmico necessário à sua realização.

\section{Gestão pedagógica na Educação a Distância}

A abordagem aqui adotada parte da ideia ampliada de gestáo de sistemas educacionais, centrando o estudo na intersecçáo entre a gestáo e a pedagogia. O conceito que referencia gestáo pedagógica é o de Martins (2007, p. 3):

A gestáo pedagógica situa-se entre os níveis macro e micro e dá-se como mediaçáo que possibilita o estabelecimento de mecanismos e iniciativas desencadeadoras de processos pedagógicos, isto é, orientados pelas finalidades da educaçáo superior e da Instituiçáo, que envolvem o ensino, a aprendizagem, o currículo, os professores e gestores acadêmicos.

A gestáo pedagógica está ligada a um conjunto de condiçóes e meios para assegurar o ensino e a aprendizagem, procurando atingir os objetivos do projeto pedagógico. Esta gestáo propicia a reuniáo, articulaçáo e integraçáo de açóes e das atividades das equipes que atuam na $\mathrm{EaD}$, por meio do planejamento, da organizaçáo, do acompanhamento e da avaliaçáo.

O trabalho de gestão pedagógica exige o exercício de múltiplas competências dos mais variados matizes. Centramos nosso estudo na intersecçáo 
entre a gestấo e a pedagogia. Segundo Souza e Cardoso (2007), a coordenaçấo pedagógica é responsável pela articulaçáo do trabalho pedagógico, visando ao trabalho coletivo, ao planejamento e à avaliaçáo do processo. Para Souza e Cardoso, "a equipe pedagógica é a responsável por articular, junto aos demais atores da organizaçáo escolar, a construçâo e implementação do projeto político pedagógico" (SOUZA; CARDOSO, 2007, p. 95). Quando se trabalha nesta perspectiva, organizam-se espaços de discussão entre os professores e as equipes, buscando uma genuína troca de informaçóes e de reflexóes. Esta dinâmica privilegia o trabalho e a discussáo coletiva.

Uma coordenaçáo pedagógica a partir desta perspectiva é ancorada a partir de uma visáo sistêmica do processo, compreendendo cada um dos espaços que integram o sistema de $\mathrm{EaD}$ de forma dinâmica e inter-relacionados. Nesse sentido, uma visáo sistêmica da $\mathrm{EaD}$ permite coordenar os esforços para responder aos desafios em conjunto.

A gestão pedagógica proposta ancora-se nos princípios do trabalho colaborativo e da horizontalidade nas decisōes; assim, "realiza-se como coordenação, isto é, pressupóe organização conjunta que articula diversos níveis hierárquicos e segmentos em torno de propósitos comuns" (MARTINS, 2007, p. 3).

Empregamos o significado do termo colaboraçáo, neste caso, como o anuncia a sua própria etimologia: "1) o trabalho em comum com uma ou mais pessoas. 2) ato de colaborar; cooperaçáo.” (COLABORAÇĀO, 1996, p. 166). Um sinônimo adequado para colaboração seria cooperação. No trabalho colaborativo, parte-se da ótica do interesse coletivo em detrimento ao interesse individual, uma vez que as relaçóes estruturadas sobre a colaboraçáo "pressupóem uma descentraçáo do pensamento no sentido de haver uma coordenaçáo entre diferentes pontos de vista (diferentes ideias), discussão e controle mútuo dos argumentos." (COSTA, FAGUNDES; NEVADO, 1998, p. 4).

Para Almeida (2005, p. 4), a colaboraçáo envolve muito mais que compartilhar informaçóes; "Envolve participação co-responsável na elaboraçáo conjunta de planos e propostas de açáo", abrindo espaços para emergir "relacionamentos de confiança mútua e cumplicidade, o comprometimento e o reconhecimento de interdependência".

A nossa proposta de sistema colaborativo na educaçáo a distância compóe uma tríade: 
Figura 1 - Tríade de sistema colaborativo

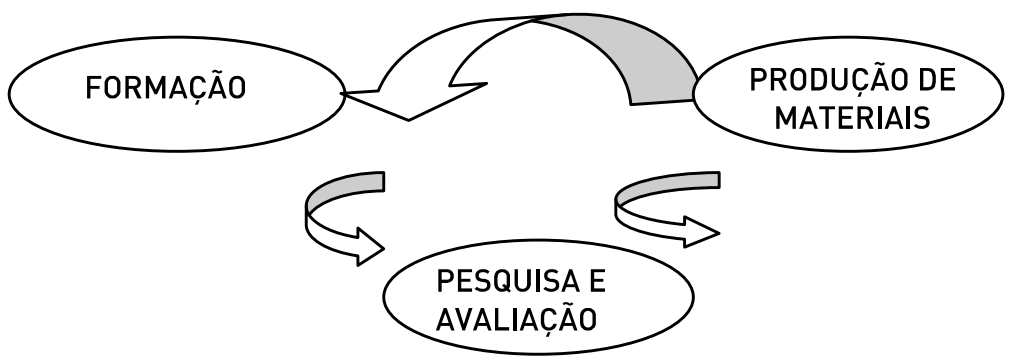

Fonte: CERNY, 2009.

No sistema proposto, a formação e a pesquisa e avaliação são açóes planejadas intencionalmente, estáo presentes em todos os momentos dos projetos dos cursos a distância, retroalimentando todo o sistema. Outra característica desse sistema é a descentralizaçấo das açóes com os centros responsáveis pelos cursos assumindo integralmente todas as açóes requeridas no trabalho com EaD.

\section{A pesquisa}

A proposta deste estudo é analisar um sistema de gestáo de cursos de graduaçáo, na modalidade a distância, com ênfase na gestáo pedagógica. Os referenciais da pesquisa embasam-se nos teóricos Michael Bakhtin (2000), Gutiérrres e Pietro (1998).

Na análise de Freitas; Souza; Kramer, (2007), Bakhtin entende a pesquisa como uma relaçáo entre sujeitos, em perspectiva dialógica, e que assume a interaçáo entre pesquisador e pesquisado como um ponto fundamental no estudo dos fenômenos humanos. Bakhtin ressalta, ainda, a necessidade de compreender os fenômenos a partir dos signos (textos) produzidos pelo homem, enfatizando o caráter interpretativo dos sentidos construídos.

Amorim (2007) lembra que "assumir o caráter conflitual e problemático da pesquisa nas Ciências Humanas implica em renunciar a toda ilusão de transparência: tanto do discurso do outro quanto do seu próprio." (AMORIM, 2004, p. 12). Entáo, organizar a pesquisa tendo clareza da opacidade dos discursos e dos textos é o primeiro passo para que a pesquisa encontre na 
diversidade "um elemento constituinte do pensamento e não apenas um aspecto secundário" (AMORIM, 2004, p. 12).

Quando se trabalha com a análise dos dados da pesquisa tendo como suporte esta teoria, ela nos remete, com frequência, para fora do texto, e o olhar privilegia o contexto que nos cerca, dialogando com os atores e autores envolvidos na prática. É importante salientar que Bakhtin náo propóe uma técnica de análise ou um método, mas uma fundamentaçáo filosófica. Seus estudos apontam sempre para uma tripla articulaçáo entre o ético, o estético e o epistemológico. A dimensáo estética é a história, e o sentido ético é o horizonte de possibilidades. Tais conceitos trabalhados articuladamente permitem uma reflexáo entre saberes. Já a dimensáo epistemológica tem origem nestes dois primeiros planos, o ético e o estético. Remetendo às palavras de Amorim (2007, p. 12): "Nas Ciências Humanas conjugam-se as dimensóes ética e estética para dar origem a outra dimensão que é a epistemológica". O que torna um pensamento ético é assumir a responsabilidade por ele perante os outros, é assiná-lo e tornar o pensamento um ato. A dimensão estética é o acabamento, sendo necessária para evitar uma abordagem simplificada do texto. Segundo Bakhtin (1993, p. 15), é impossível compreender a singularidade de um texto "sem uma concepçáo sistemática do campo estético, tanto no que o diferencia do campo do cognoscível e do ético, como no que o liga a eles na unidade da cultura".

Existe uma realidade que precisa ser analisada, descrita, desvelada, conhecida, interpretada, criticada e compreendida, a qual está em permanente movimento, constituindo um processo em constante transformaçáo. $\mathrm{O}$ pesquisador, entâo, dá um sentido à realidade, o que "é potencialmente infinito, mas só se atualiza no contato com outro sentido (o sentido do outro), mesmo que seja apenas no contato com uma pergunta no discurso interior do compreendente." (BAKHTIN, 2000, p. 386, grifo do autor).

Tal é a opçáo desta pesquisa: mostrar, a partir do lugar ocupado, o que foi vivenciado na condiçẫo de coordenadora pedagógica de educaçáo a distância. De uma reflexáo sobre as questóes, os dados e as análises, investigamos um sistema de gestáo para $\mathrm{EaD}$ que contemple uma metodologia de gestáo pedagógica para educaçáo a distância, caracterizando esta modalidade especialmente como um processo sistêmico e visando à democratizaçáo da educaçáo.

\section{O método: a auto-observação}


Fundamentadas na teoria Bakhtiniana, trazemos à contribuição os teóricos Delgado e Gutiérrez (1998) e sua proposta metodológica: a auto-observação, a qual se constitui num procedimento de aprendizagem e conhecimento inverso ao realizado na observação participante. $\mathrm{Na}$ observaçáo participante, o pesquisador aprende a ser um "nativo" de uma cultura estranha, é um observador externo que pretende inserir-se como participante de uma determinada experiência. $\mathrm{Na}$ auto-observaçáo, o pesquisador aprende a ser um observador da sua própria cultura, pois ele é um nativo desta cultura. O termo "nativo", utilizado pelos autores, significa aquele que faz parte do sistema a ser analisado na pesquisa.

O auto-observador, no papel de nativo de um sistema, deve ocupar o maior número possível de posiçôes como ator-observador, possibilitando a análise mais aprofundada do objeto examinado. O pesquisador náo parte de hipóteses predefinidas, de atitudes intencionais de captar apenas recortes da realidade, mas procura captar a indeterminaçáo do objeto ocasionada em diferentes tempos de leitura e escrita. O "texto nativo" conta com a responsabilidade do sujeito-ator e sua participaçáo na realidade estudada.

Delgado e Gutiérrez (1998) apontam dois conceitos principais para a fundamentaçáo epistemológica da auto-observação: a certeza e o sentido, uma vez que a certeza e a compreensáo dos sentidos sáo os fundamentos que conferem validade à auto-observaçáo e a partir dos quais a pesquisa se realiza.

Do conceito de certeza procuramos compreender as açóes dos sujeitos envolvidos na pesquisa, atribuindo sentido a suas falas. O conceito de sentido traz a referência à atividade seletiva heterogênea do pesquisador, caracterizada por sua interpretaçáo criativa dada aos contextos complexos e históricos do objeto estudado. A atribuiçáo de sentido dada ao objeto, assim como as relaçóes que os objetos mantêm entre si, sáo resultado do processo de objetivaçáo que o pesquisador faz, ele atribui um significado a partir do diálogo com o outro.

\section{O diálogo com o outro}

Esta pesquisa compreende o acompanhamento das açóes realizadas na implantaçáo da $\mathrm{EaD}$ em uma instituiçáo de ensino federal e procura analisar, a partir da perspectiva da pesquisadora e gestora, a trajetória de implantaçáo dos primeiros cursos de licenciatura na modalidade a distância. Esta análise traz as vozes dos gestores que integram o sistema de educaçáo a distância estudado. Foram entrevistados sete gestores: reitor, vice-reitor, diretores de 
centro, secretário de $\mathrm{EaD}$ e coordenadores de curso.

Assumindo a posiçáo exotópica, analisamos os dados a partir de duas categorias: as certezas e os sentidos, sendo as certezas as falas dos pesquisados, e os sentidos, as análises realizadas. A noçáo de construçáo de sentido será utilizada para as reflexóes sobre o sistema de educaçáo a distância observado. Os sentidos seráo construídos no diálogo com o outro, na construçáo de conhecimento, nas ideias partilhadas a partir do entrecruzamento de fatos e de depoimentos. As certezas sáo originárias das entrevistas e das falas dos pesquisados, e o objetivo náo será o de avaliar, mas o de analisar, apresentar, ordenar e interpretar a situaçáo a partir dos dados obtidos com os diferentes informantes na pesquisa, visando a fazer emergir os significados que se construíram nas situaçóes estudadas.

\section{A construção das certezas e sentidos a partir do diálogo com o outro}

Nas entrevistas realizadas com gestores, três anos após o início das atividades, os dirigentes da instituiçáo consideram que a opçáo pela descentralizaçáo das açóes foi a mais acertada:

Conseguimos! A gente evoluiu, se a gente voltar dois anos atrás, ver o que tínhamos de ensino a distância, de graduaçáo na UFSC, era zero. Hoje está no CED, tá dentro do CFM, da Matemática, da Física, da Química, no CCE, na Administraçáo. É uma coisa fantástica! (gestor).

O modelo de educaçáo a distância que eu acho que está correto éo departamento "A" que vai trabalhar com educaçáo a distância, vai ter a sala de videoconferência, ele vai produzir, ele náo vai ficar contratando fulano e beltrano, eu tenho que ter uma responsabilidade institucional da educaçáo a distância e por isso pensar numa estrutura que seja da instituiçáo, que passe pela instituiçáo e que seja descentralizada. Ao mesmo tempo em que envolva as pessoas (gestor).

Hoje se cria uma nova estrutura com dois braços, uma vinculada à formaçāo de professores, das licenciaturas, 
que vai ter uma legislação, vai estar vinculada a uma pró-reitoria; e uma outra, outro braço, mais flexivel, sem vinculos orçamentários, de gestão mais personalizada. Então, até que se prove ao contrário, esta estrutura não está submetida às instâncias institucionais. E vão dar cursos de especialização, capacitação, atender às demandas de empresas (gestor).

Essas falas configuram a dualidade do processo. O discurso político da administraçáo central é o de descentralizaçáo das açóes, mas, na prática, estes mesmos dirigentes criam departamentos que centralizam as açóes e inibem o projeto aprovado de um sistema descentralizado. Os dirigentes dos centros de ensino sáo receosos sobre a continuidade do processo descentralizado.

Nesse entorno, os conflitos entre o acordado e os propósitos políticos refletem-se nas práticas do cotidiano, configurando-se o paralelismo das açóes de $\mathrm{EaD}$ na universidade, pois esta situa-se, também, em outras instâncias (informais) da instituiçáo. O estilo de gestáo adotado pela instituiçáo irá determinar as práticas e formas de relacionamento entre todos os que atuam no sistema, interferindo diretamente no ensino e na aprendizagem.

Além das discussóes sobre a organizaçáo pedagógica e administrativa das graduaçóes a distância na universidade, um fator que influencia diretamente nas decisóes é o modo como a modalidade é vista na instituiçáo, o que auxilia e o que inibe as açóes. O grande desafio para projetos desta natureza é a mudança cultural, pois a mudança da cultura tradicional na instituiçáo garantirá inovaçóes na prática docente, necessárias à atuaçáo em cursos na modalidade a distância. Estas inovaçóes ocorrem como um processo de transição entre a prática tradicional e as novas possibilidades de reconstruçóes. Embora seja importante considerar a influência destes, a universidade, pela sua própria história e modo como está estruturada pedagógica e administrativamente, tende a oferecer entraves para a realização de mudanças.

Os dirigentes entrevistados apontam, como motivos que dificultam a adoçáo da $\mathrm{EaD}$ na instituiçáo, a cultura, a burocracia institucional, o hábito de trabalhar no presencial e, com mais ênfase, a história da $\mathrm{EaD}$ vivenciada na UFSC:

A primeira dificuldade [para a adoçāo da EaD na instituição] é setorial. A maior dificuldade, ainda, é 
cultural-na minha concepção. As pessoas não sabem o que $e ́$, não querem saber o que é e sáo contra. Interpretam como uma fragilização, como um caminho preferencial de menor esforço. Náo é nada disso; felizmente a gente tem sido feliz na UFSC, diminuido resistência, as pessoas mais refratarias têm encampado. Agora a gente está numa segunda etapa: etapa de moldagem. Tem pessoas que defendem o ensino a distância, trabalham no ensino a distância [...] (gestor).

A dificuldade cultural refere-se, especialmente, às posiçóes dos professores sobre a educaçáo a distância, que, em muitos casos, têm sido contrárias à sua adoçáo como modalidade de ensino. O quadro que se manifesta está ideologicamente condicionado por desconhecimento ou pela história que a modalidade tem em nosso país e na universidade.

Há discordâncias náo apenas conceituais sobre o que seja educaçáo a distância, mas também sobre o espaço que esta modalidade vem ocupando na universidade e no cenário da educaçáo brasileira. A EaD vem ocupando um lugar de destaque nas políticas públicas da educaçáo brasileira, principalmente a partir de 2005, quando o atual governo elege esta modalidade para a formaçáo de professores em todos os níveis.

A maior dificuldade [para o desenvolvimento da EaD na instituiçáo], eu acho que é o passado. A história. Essa história ainda está muito presente. Nessa história incuto a duas variáveis: a primeira, uma lógica da própria área onde surgiu a educaçáo a distância - que era a engenharia de produção -, e a outra associada à educação a distância - associada a um modelo de produçáo em série, e por isso tinham muitos recursos. E esses recursos eram mais flexiveis, em termos de gestáo orçamentária. E isso gerou muitas dúvidas sobre o uso desse dinheiro. A gente paga um preço até hoje, tem histórias daquele modelo de gestáo propriamente do setor que cuidava da produçáo de materiais. (gestor).

Que história é esta que marca profundamente essa modalidade de ensino? É preciso buscar entender esta história, não só em sua singularidade constitutiva, mas na sua extensão, para evitar continuar contemplando um passado como se ele fosse presente, mas também não destituí-lo de sua importância como fonte 
e como história. Sobre este aspecto, vale lembrar a história da modalidade a distância desta universidade, que iniciou centralizando a $\mathrm{EaD}$ em um único laboratório, que oferecia autonomamente, inclusive, cursos de formaçáo de professores sem uma parceria com os centros responsáveis, gerando uma prestação de serviços dentro da própria instituiçáo.

Consideramos que é uma opçáo teórica entender o passado como constituinte da história e da cultura. É necessário que cada um assuma a responsabilidade na condiçáo de participantes da história construída, pois, na realidade estudada, a história é construída, também, com a negaçáo da modalidade pelos centros responsáveis pela formaçáo de professores. A história da $\mathrm{EaD}$ também está associada ao preconceito e à insegurança dos educadores, tendo sido por muito tempo associada à educaçáo de massa sem qualidade.

Outro aspecto evidenciado por este gestor está ligado à liberaçáo dos recursos financeiros para os projetos de $\mathrm{EaD}$ : como náo se trata de uma modalidade regular, os recursos sáo descentralizados para projetos e sáo administrados em sua maioria pelas fundaçóes de apoio, permitindo que o ordenamento financeiro seja realizado sem uma fiscalização sistemática dos colegiados já instituídos na universidade. Esse fato aponta para a necessidade de um olhar mais cuidadoso nas políticas públicas desta área, que podem estar contribuindo para a criaçáo de uma "universidade paralela", sem o compromisso de atuar no ensino, na pesquisa e na extensão, situando a universidade como uma "mera prestadora de serviços". (PRETTO, 2005, p. 37).

Corroborando o depoimento anterior, outro gestor enfatiza novamente, como fator inibidor da implantaçáo da $\mathrm{EaD}$, a história da modalidade na UFSC:

Um dos primeiros problemas [na implantação da $E a D$ ] foi organizar minimamente of funcionamento disso, como ele entra - é extensáo? A organização do quadro de pessoas que váo atuar foi um problema muito grande. De outro lado, é você receber um financiamento com várias limitaçóes de execução, uma lógica velha para uma nova açáo. Outra questão é a política de organizaçāo, que é um problema da nossa instituiçáo. Por pressóes, tivemos que iniciar o curso sem as condiçóes necessárias. Há também um preconceito muito grande da comunidade cientifica com a modalidade; apesar de já lidarem com a tecnologia, náo sáo capazes de perceber o potencial [da EaD] para a educação. Temos duas 
posiçóes no departamento: aqueles que não acreditam que é possivel fazer EaD e outra que é contra porque é contra. Esses preconceitos sáo reforçados pela nossa história, pois o Centro de Ciências Físicas e Matemáticas participou numa primeira experiência de educação a distância que não foi gerenciado pelo Centro e em termos de educaçáo a distância foi um desastre, e isso não deixou ganhos e possibilidades, só reforçou os preconceitos (gestor).

Percebem-se, no discurso deste gestor, vários pontos em comum com o depoimento dos outros gestores sobre a dificuldade na implantaçáo do sistema $\mathrm{EaD}$ na instituiçáo: a organizaçáo, o financiamento, as políticas e a história, fatores estes que podem ser considerados interdependentes.

Nos depoimentos colhidos, é notável que a educaçáo a distância em exercício guarda marcas de todas estas vertentes.

\begin{abstract}
Eu acho que [em relaçáo às dificuldades enfrentadas na EaD] náo é só as resistências dos segmentos mais conservadores da universidade, mas é também a defesa do seu espaço como professor do presencial. Mas eu acho que é a burocracia. Às vezes me dá impressáo que todo dia precisamos fazer virar uma máquina para resolver uma coisinha (gestor).
\end{abstract}

Este gestor destaca um aspecto importante presente, especialmente, nas instituiçóes públicas: a burocracia. Porém, considero que, neste caso, a burocracia refere-se muito mais à falta de normas internas na instituição para sustentar a modalidade. Se for analisada a área organizacional das universidades, será possível verificar que o modelo vigente favorece o desenvolvimento de práticas burocráticas, individualistas e hierarquizadas e, quando se incorpora a $\mathrm{EaD}$ nestas instituiçóes, estes fatores estarão presentes.

Nestes relatos, evidencia-se que as principais dificuldades para a implantaçáo da educaçáo a distância na UFSC, segundo os gestores entrevistados, sáo: a história da $\mathrm{EaD}$ na instituiçáo, marcada pela centralizaçáo do processo em um único laboratório de $\mathrm{EaD}$, gerando uma prestaçáo de serviços dentro da própria instituiçáo; a cultura do presencial; a organizaçáo institucional pouco flexível; o financiamento que é administrado sem o acompanhamento direto dos centros envolvidos; as políticas públicas que "engessam" a autonomia das universidades na organizaçáo e gestáo da EaD, 
contribuindo para a criaçáo de uma universidade paralela dentro da mesma instituição; e f) a burocracia. O item mais citado está relacionado à história da EaD na UFSC.

\section{A equipe multidisciplinar da Coordenação Pedagógica}

A equipe da Coordenação Pedagógica foi concebida em dezembro de 2004 e iniciou suas atividades em janeiro de 2005. A equipe é integrada por professores do CED e do CFM e por alunos dos cursos de graduaçáo e pósgraduaçáo da UFSC. A contrataçáo dos alunos deve-se à maneira como os recursos sáo descentralizados para as universidades. Os recursos sáo repassados para as fundaçóes de apoio, e a alternativa é a contratação dos estudantes como bolsistas, visto que o contrato trabalhista geraria um custo adicional náo previsto, inicialmente, nos projetos de educaçáo a distância.

Trabalhar com os alunos da universidade traz pontos positivos e negativos. Um ponto positivo é a formação dos estudantes para uma área em crescimento, e um ponto negativo é o fato de os estudantes saírem para o mercado de trabalho no momento em que estáo integrados à equipe e com conhecimento experiente do trabalho em $\mathrm{EaD}$.

O objetivo da equipe sempre foi o de náo ser uma mera prestadora de serviços, e sim um grupo no qual os profissionais sáo parceiros entre si e de outros centros de ensino no planejamento e no desenvolvimento de materiais. Para os gestores, o modelo de parceria entre os centros responsáveis pela formaçáo de professores é interessante, conforme pode ser verificado neste depoimento:

Eu acho que essa coisa de a EaD estar dentro CED como apoio pedagógico é um pouco reprodução do nosso modelo de atuaçáo nos cursos de licenciatura presenciais, sem com isso estar reproduzindo algo que a gente condena há muito tempo, que é o velho sistema de sobreposiçāo das atividades pedagógicas das atividades de conteúdo dos cursos. $O$ Centro de Educaçáo fornece as disciplinas pedagógicas aos departamentos de origem. Náo queremos isso! Aqui é um movimento contínuo, permanente de reconhecimento por parte dos professores das áreas específicas, na elaboraçáo do material, na organizaçáo do curso, na preparaçáo das pessoas para atuarem na educação a distância, entáo acho que é um 
modelo interessante (gestor).

A percepçáo de que a gestáo pedagógica reproduz em parte o modelo vivenciado no presencial é considerado um ponto positivo, porém, o gestor lembra que não se pode reproduzir o que se condena há muito tempo: a sobreposiçấo das atividades pedagógicas e das atividades de conteúdo dos cursos. O caminho almejado é a construçáo de uma estrutura que dialogue com o presencial e, consequentemente, que ambas as modalidades sejam otimizadas. No entanto, este não é um processo simples de ser construído, pois tradicionalmente os centros de ensino organizam-se independentemente nas suas atividades. $\mathrm{O}$ impacto inicial de trabalhar em parceria registra-se no depoimento a seguir:

Eu acho que [a parceria entre centros], pelo inicio, como aconteceu, a Física entrou primeiro no trabalho com o $C E D$, a gente entrou meio pela tangente, eu me senti excluida do processo. Tive muita dificuldade, no comę̧o, de compreender as funçöes da parceria, de ambas as partes, e até de entendimento do que temos nos cursos de graduaçäo presenciais, da estrutura, como funciona dentro da instituição. Eu senti tanto da equipe de coordenaçáo pedagógica a dificuldade de perceber a estrutura e também de aceitar a parceria. Entäo, no andamento, passou-se a respeitar um ao outro e o trabalho ficou muito bom. (gestor).

A construção coletiva do trabalho demanda tempo, flexibilidade e abertura por parte das equipes para a construçáo de novas formas de trabalhar. Compartilhar espaços e atividades coletivamente é uma tarefa náo exercitada na universidade, pois as alteraçóes trazidas por meio das políticas, nos últimos anos, fazem com que elas se voltem para elas mesmas, competindo internamente (CHAUÍ, 2001). Portanto, trabalhar coletivamente revela-se um exercício de construir as parcerias e reafirmá-las rotineiramente. O que contribui significativamente para o avanço deste trabalho é a tomada de decisáo conjunta.

Emerge, como sentido na organizaçáo da equipe multidisciplinar da coordenaçáo pedagógica, o fato de que a gestáo pedagógica reproduz em parte o modelo de parceria entre os centros formadores de professores vivenciado no ensino presencial; porém, a construçáo coletiva do trabalho requer tempo, flexibilidade e abertura por parte das equipes para a construçáo de espaços 
compartilhados. A formaçáo de parcerias é o primeiro passo, seguido de um exercício permanente de decisóes conjuntas para reafirmá-las.

\section{Conclusão}

Um texto de pesquisa em Ciências Humanas não se encerra, mas abre possibilidades e, quiçá, este texto instigue muitos outros. Retomamos aqui Bakhtin, para lembrar que o texto do pesquisador é texto sobre texto, é discurso sobre discurso, constituindo um lugar de encontro de discursos.

O sistema de gestáo pedagógica analisado ancora-se na tríade formação, produçáo de materiais e pesquisa e avaliaçáo. Nesta proposta, trazemos como possibilidade náo tratar a $\mathrm{EaD}$ como ação paralela ao ensino presencial, mas como uma oportunidade de integrar e potencializar ambas as modalidades, assim contribuindo para repensar as práticas pedagógicas estabelecidas há muito tempo. $\mathrm{O}$ desenvolvimento de projetos de educaçáo numa dimensáo colaborativa entre os sistemas de ensino presencial e de educaçâo a distância amplia novas possibilidades às equipes responsáveis, permitindo que estas se unam para estabelecer pautas e acordos de trabalho. Nesse sentido, a educaçáo a distância passa a ser considerada no contexto da educaçáo e, portanto, necessariamente vinculada ao contexto histórico, político, educacional e social no qual esta prática se realiza.

$\mathrm{Na}$ análise sobre a implantaçáo do sistema de gestáo da EaD na UFSC em cursos de licenciatura - mais precisamente os Cursos de Licenciatura em Física e Matemática -, evidenciei que a mesma apresentou dificuldades relacionadas à definiçáo das suas políticas, marcadas pela centralizaçáo dos processos, que, apesar de náo estarem presentes no discurso dos dirigentes, materializam-se em açóes: foram criadas e organizadas estruturas paralelas àquelas previamente acordadas, gerando indefiniçáo sobre os papéis que cada equipe deveria desempenhar.

As principais dificuldades para a implantaçáo de cursos de graduaçáo a distância, segundo os gestores entrevistados, sáo: a história da EaD nesta instituiçáo, a cultura do presencial, o modelo pouco flexível de organizaçáo institucional, o modo como os financiamentos sáo descentralizados e administrados, as políticas públicas e a burocracia. O item mais citado refere-se à história da EaD na UFSC.

Mesmo cientes de todas estas dificuldades, os gestores da instituição

PERSPECTIVA, Florianópolis, v. 30, n. 1, 19-39, jan./abr. 2012

http://www.perspectiva.ufsc.br 
aderem à política do Governo Federal de formaçáo de professores por meio da $\mathrm{EaD}$, e os fatores que os motivam a esta decisáo sáo: o compromisso político com o ensino público em seus diferentes níveis, convertidas em açóes de ressignificaçáo do papel da universidade pública, as quais conferem uma possibilidade de ir além de uma postura de denúncia e apontam para a construçáo de políticas em direção à mudança no âmbito das instituiçóes de ensino superior; a interiorizaçâo da universidade pública e a ampliação do número de vagas; e a formaçấo emergencial de professores com vistas à melhoria da educaçáo básica.

$\mathrm{Na}$ organizaçáo da equipe multidisciplinar, observamos que a gestáo pedagógica reproduz em parte o modelo vivenciado no ensino presencial quanto à parceria entre os centros formadores de professores; a construçáo coletiva do trabalho, porém, demanda tempo, flexibilidade e abertura por parte das equipes. Além da realizaçáo de parcerias democráticas, há que se manter um exercício permanente para reafirmá-las, por meio de decisóes conjuntas.

\section{Notas}

1 Estes dados podem ser conferidos no Relatório produzido pela Comissão Especial instituída para estudar medidas que visem a superar o déficit docente no ensino médio. A comissão foi integrada pelos conselheiros Antonio Ibañez Ruiz (presidente), Mozart Neves Ramos (relator) e Murílio de Avellar Hingel.

2 Das 1.637 instituiçóes de ensino superior no Brasil, 195 são públicas e 1.442 privadas. Fonte: MEC, Prouni, 2004 (BRASIL, 2004).

\section{REFERÊNCIAS}

ALMEIDA, M. E. B. O relacionamento entre parceiros na gestáo de projetos de educação a distância: desafios e perspectivas de uma açáo transdisciplinar. In: CONGRESSO MUNDIAL DE TRANSDISCIPLINARIDADE, 2., 2005, Vitoria, ES. Anais...Vitória, ES, 2005. 1 CD-Rom.

AMORIM, M. O pesquisador e seu outro: Bakhtin nas ciências humanas. 2. reimp. São Paulo: Musa, 2004.

AMORIM, M. A contribuiçáo de Mikhail Bakhtin: a tripla articulaçáo ética, 
estética e epistemológica. In: FREITAS, M. T.; SOUZA, S. J.; KRAMER, S. (Org.). Ciências Humanas e pesquisa: leituras de Mikhail Bakhtin. São Paulo: Cortez, 2007. p. 11-25. (Coleçáo da nossa época).

BAKHTIN, M. M. Estética da criação verbal. 3. ed. Sáo Paulo: Martins Fontes, 2000.

BAKHTIN, M. M. O problema do conteúdo, do material e da forma na criaçáo literária. In: Questóes de literatura e estética: a teoria do romance. Traduçáo de A. F. Bernadini et al. 3. ed. Sáo Paulo: Ed. da Unesp, 1993[1924]. p. 13-70.

BRASIL. Ministério da Educaçáo. Programa de formação inicial para professores em exercício no ensino fundamental e no ensino médio - PróLicenciatura: propostas conceituais e metodológicas. Brasília, 2005. Disponível em: <http://portal.mec.gov.br/seb/arquivos/pdf/pro_licenciatura. pdf $>$. Acesso em: 14 dez. 2008.

CERNY, R. Z. Gestão pedagógica na educação a distância: análise de uma experiência na perspectiva da gestora. Tese de doutorado apresentada ao Setor de Pós-Graduação da Pontifícia Universidade Católica de Sáo Paulo PUC/SP. São Paulo, 2009.

CHAUÍ, M. Escritos sobre a universidade. São Paulo: Ed.UNESP, 2001.

COLABORAÇÃO. In: FERREIRA, A. B. H. Miniaurélio: o minidicionário da língua portuguesa. 6. ed. rev. amp. Curitiba: Posigraf, 2004. p. 166.

COSTA, I. E. T.; FAGUNDES, L. C.; NEVADO, R. A. Educaçáo à distância e a formaçâo continuada de professores em sistemas de comunidades de aprendizagem. Campinas: Unicamp, 1998. Disponível em: <http://www. nied.unicamp.br/oea/mat/ead_forma\%E7\%E3o_teclec_.pdf $>$. Acesso em: 14 dez. 2008.

DELGADO, J. M.; GUTIÉRREZ, J. (Ed.). Métodos y técnicas cualitativas de investigación enm ciencias sociales. Espanha: Sintesis, 1998. (Metodología de las ciencias del comportamiento).

FREITAS, M. T.; SOUZA, S. J.; KRAMER, S. (Org.). Ciências humanas e pesquisa: leituras de Mikhail Bakhtin. 2. ed. São Paulo: Cortez, 2007. (Questóes da nossa época, v. 107).

PERSPECTIVA, Florianópolis, v. 30, n. 1, 19-39, jan./abr. 2012 http://www.perspectiva.ufsc.br 
GUTIÉRREZ, J.; DELGADO, J. M. Teoría de la observación. In: DELGADO, J. M.; GUTIÉRREZ, J. (Ed.). Métodos y técnicas cualitativas de investigación en ciencias sociales. Espanha: Sintesis, 1998. cap. 6, p. 141-173. (Metodología de las ciencias del comportamiento).

MARTINS, M. A. R. Gestão pedagógica de cursos de graduação: a instituição de educação superior como espaço de formaçáo contínua de professores e gestores acadêmicos. In: SIMPÓSIO BRASILEIRO DE POLÍTICA E ADMINISTRAÇĀO DA EDUCAÇÃO, 23.; CONGRESSO LUSO-BRASILEIRO DE POLÍTICA E ADMINISTRAÇĀO DA EDUCAÇĀO, 5.; COLÓQUIO IBERO-AMERICANO DE POLÍTICA E ADMINISTRAÇĀO, 1., 2007, Porto Alegre. Anais eletrônicos... Porto Alegre, 2007. Disponível em: <http://www.isecure.com.br/anpae/270.pdf>. Acesso em: 14 dez. 2008.

PRETTI, O. Educaçáo a distância: uma prática educativa mediadora e mediatizada. In: _. Educação a distância: início e indícios de um percurso. Cuiabá: NEAD/IEUFMT, 1996.

PRETTO, N. L.; PICANÇO, A. A. Reflexóes sobre EaD: concepçóes de educaçáo. In: ARAÚJO, B.; FREITAS, K. S. Educaçâo a distância no contexto brasileiro: algumas experiências da UFBA. Salvador: ISP/UFBA, 2005. p. 31 56.

SOUZA, A. M. B.; CARDOSO, T. M. Organização escolar. Florianópolis: UFSC/EAD/CED/CFM, 2007. 


\section{Pedagogical administration Gestión pedagógica en in distance education: la educación a distancia: analysis of an experience análisis de una experiencia from the perspective of an en la perspectiva de la administrator gestora}

\section{Abstract}

This paper analyses the pedagogical administration system used at a public institution of higher education during the implementation of its first distance education accreditation courses. The theoretic principals are based on references from educational system administration. The system was created based on the idea of collaborative work and anchors itself on the three elements: education, materials production and research and evaluation. A qualitative methodology was used and the method chosen was self-observation. The analysis made clear that the main difficulties for the implementation of distance education courses are: the history of distance education, the culture of presence, the somewhat inflexible model of institutional organizations, bureaucracy and public policies. In the organization of the teams there is the perception that educational administration partially reproduces the classroom model in terms of the partnership between teacher education institutions. The study revealed that the collective construction of work demands time and openness by the teams involved. It is possible to conclude that the integrated work of education, the

\section{Resumen}

El artículo analiza un sistema de gestión de la educación desarrollado en una institución pública de Educación Superior durante la implementación de los primeros cursos de graduación a distancia. Los fundamentos teóricos tienen como base el referencial de gestión de los sistemas educacionales. El sistema fue construido a partir de la perspectiva de un trabajo colaborativo anclado en la tríada formación, producción de materiales e investigación y evaluación. La metodología de investigación es la cualitativa y el método es de auto observación. En el análisis se evidencio que las principales dificultades para la realización de cursos a distancia son: la historia de la Educación a Distancia, la cultura de lo presencial, el modelo poco flexible de organización institucional, las políticas públicas y la burocracia. En la organización de los equipos existe la percepción de que la gestión de la educación reproduce en parte el modelo que se da en la educación presencial, en lo que concierne a la colaboración entre los centros formadores de profesores. Se constató que la construcción colectiva del trabajo exige tiempo y apertura por parte de los equipos. Es posible concluir que el trabajo integrado de formación, 
production of materials and research and evaluation contribute to a more organic performance in distance education, breaking the Fordist paradigms normally found in experiments with this learning modality.

Keywords: Distance education. Pedagogiccal management. Teacher training. de producción de materiales y de investigación y evaluación, contribuye para una actuación más orgánica en la educación a distancia, rompiendo los paradigmas fordistas que se encuentran en las experiencias con esta modalidad de enseñanza.

Palabras clave: Educación a distancia. Gestión de la educación. Formación de profesores.

\section{Roseli Zen Cerny}

E-mail: rose@ced.ufsc.br

Maria Elisabeth Bianconcini de Almeida

E-mail: bbalmeida@uol.com.br

Recebido em: 22/2/2011

Versáo final recebida em: 26/9/2011

Aprovado em: 3/2/2012 